Historia y comunicación social

ISSN-e 1988-3056

https://dx.doi.org/10.5209/hics.66304

\title{
De la atomización de la programación a los magacines: los espacios ligeros en la radiodifusión de las Islas Canarias durante el franquismo
}

\author{
Julio Antonio Yanes Mesa ${ }^{1}$
}

Recibido: 24 de septiembre de 2017. / Aceptado: 11 de septiembre de 2018.

Resumen. En el franquismo, los programas ligeros de la radiodifusión canaria no dieron señales de vida hasta que el régimen distendió, en plena II Guerra Mundial, la propaganda bélica tras la debacle nazi en Stalingrado, para luego consolidarse, en coincidencia con las primeras medidas aperturistas, bajo una estructura "mosaico". La posterior expansión, desde la inauguración de Radio Juventud de Canarias (1955), de la música discográfica y las mejoras socioeconómicas traídas por el boom turístico propiciaron la evolución, una década más tarde, de tales espacios hacia magacines de larga duración. Junto a los factores contextuales y técnicos que hicieron posible tal mutación, rescatamos los hitos más relevantes del proceso y las especificidades isleñas dentro del contexto estatal.

Palabras clave: franquismo; propaganda; radiodifusión; entretenimiento; Islas Canarias.

\section{[en] From disintegration of radio programming to magazines: light pots in the Canary Islands broadcasting during Franco years}

\begin{abstract}
In Franco years, there was no sign of light radio spots in Canary Islands broadcasting before the regime defused war propaganda after the Nazi debacle at Stalingrad, during WWII, and then consolidated itself under a mosaic structure in coincidence with the first opening measures. The subsequent expansion of the record music, since the inauguration of Radio Juventud de Canarias (1955), and the socioeconomic improvements brought by the tourism boom led to the evolution of such spots into long-term magazines a decade later. Together with the contextual and technical factors that made such a mutation possible, this paper recovers the most important milestones of this process and the peculiarities of the islands within the state context.
\end{abstract}

Keywords: Franco years; propaganda; broadcasting; entertainment; Canary Islands.

Sumario: 1. Planteamiento y justificación de la investigación. 2. Marco teórico y metodología; 3. La soledad de Radio Club Tenerife en los años de la autarquía. 4. La propuesta musical de Radio Juventud de Canarias en 1955. 5. El apogeo de la estructura "mosaico" en los años centrales del franquismo. 6. El tránsito hacia los primeros espacios de larga duración en Radio Club Tenerife. 7. Los magacines de Radio Juventud de Canarias y las emisoras del interior de la provincia. 8. La incorporación de Radio Club Tenerife a la cadena SER como emisora asociada. 9. Conclusiones. 10. Referencias bibliográficas.

Cómo citar: Yanes Mesa, J. A. (2019). De la atomización de la programación a los magacines: los espacios ligeros en la radiodifusión de las Islas Canarias durante el franquismo, en Historia y comunicación social 24 (2), 615-630.

Universidad de La Laguna.

jayanes@ull.edu.es 


\section{Planteamiento y justificación de la investigación}

Tras lanzar a los cuatro vientos, a través de sus equipos de onda media y corta, la proclama del general Franco que desató la guerra civil, los rebeldes convirtieron a Radio Club Tenerife EAJ-43 en el canal propagandístico más oído en el contexto internacional. El inmediato control del archipiélago, el fracaso de la insurrección en las zonas punteras de la península, la interposición entre uno y otra de casi dos millares de kilómetros de mar y el emplazamiento atlántico, hacen explicable tal resolución. Para ello, los técnicos amplificaron el alcance de la señal de la emisora con el acoplamiento del equipo de onda corta de 20 kilovatios que la compañía telefónica tenía en la isla. Finalizada la lucha fratricida y, más aún, desde el estallido de la II Guerra Mundial, Radio Club Tenerife EAJ-43 prosiguió con su campaña en favor del fascismo hasta la derrota nazi en Stalingrado, cuando el paulatino giro ideológico del régimen a remolque de la decantación de la conflagración del lado aliado aceleró, desde inicios de 1943, el progresivo acercamiento a los Estados Unidos (Yanes, 2010). En el penoso contexto de la posguerra, la estación tinerfeña recuperó su condición local y empezó a restituir en los intersticios que dejaba su labor proselitista, reducida ahora al adoctrinamiento de la audiencia local, los contenidos convencionales del medio, evidentemente, dentro de las enormes limitaciones impuestas por la crisis económica y la censura.

En los renglones que siguen, nos proponemos detectar la evolución de los programas ligeros ${ }^{2}$ de Radio Club Tenerife y las cuatro emisoras que, con posterioridad, fueron montadas en la provincia occidental del archipiélago canario en el franquismo. Nos referimos a Radio Juventud de Canarias, La Voz del Valle de La Orotava, Radio Popular de Güímar y La Voz de la Isla de La Palma; la primera inaugurada a finales de 1955 y las otras tres a mediados de 1960. La hipótesis que nos proponemos verificar, testeada en una investigación exploratoria previa en las fuentes utilizadas, nos prefigura esta secuencia en la evolución de los espacios ligeros en la radiodifusión isleña a lo largo de la dictadura: a) la irrupción de tales espacios en los años de la autarquía y su consolidación en la década de los cincuenta, en coincidencia con las primeras medidas aperturistas del régimen, bajo una estructura "mosaico"; b) el impulso de la música discográfica desde la inmediata puesta en marcha, a finales de 1955, de Radio Juventud de Canarias; y c) la gestación de los magacines de larga duración en los años sesenta, al calor de las mejoras socioeconómicas traídas por el boom turístico. Precisar esta secuenciación, detectar los factores que la hicieron posible, rescatar los hitos más relevantes de cada momento y localizar las especificidades isleñas en el contexto estatal a la luz del estado actual de los conocimientos, son nuestros objetivos específicos. En pos de ellos, echamos mano de las fuentes disponibles, cotejamos todos los datos recabados y, con las oportunas inferencias sobre la información depurada, narramos lo acontecido sobre el trasfondo del cambiante escenario tejido por la evolución de la España franquista. Como colofón, en las conclusiones resumimos la respuesta que estamos en disposición de ofrecer sobre los retos planteados en la investigación.

Al respecto debemos aclarar que, de los espacios ligeros de la época, hemos considerado oportuno dejar para otro trabajo específico, por sus singularidades, los grandes concursos y los eventos cara al público. 


\section{Marco teórico y metodología}

La programación de entretenimiento en la radiodifusión española durante el franquismo ha sido abordada tanto en las monografías globales elaboradas sobre el sector (Díaz, 1999; Balsebre, 2002), como en otras contribuciones específicas, caso del amplio panel de expertos moderado por Salvador Gómez García en el Congreso de la AE-IC celebrado en la Universidad de Málaga en 2010 (Gómez García et al, 2010). También disponemos de estudios sectoriales centrados en la música (Pedrero, 2000) y en otras vertientes del medio relacionadas, de alguna manera, con el entretenimiento, desde la evolución de las audiencias radiofónicas en el primer franquismo (Gómez García y Cabezas Deogracias, 2013) al desarrollo de la publicidad y el posterior nacimiento de la sociedad de consumo (Sebastián Morillas, 2017), pasando por el viraje ideológico de Radio Nacional de España tras la derrota de Hitler en la II Guerra Mundial (Gómez García, 2012). Paralelamente, con el avance de la investigación en todos los ámbitos del franquismo, están saliendo a relucir cada vez más los matices diferenciales internos, incluidos los territoriales, que anidaban en la España de la época, en lo que la radiodifusión no ha sido una excepción. El caso de las Islas Canarias, con su lejanía de la península, su emplazamiento en el océano Atlántico y su tradicional apertura al exterior, resulta particularmente revelador.

De la radiodifusión canaria contamos con una monografía que, exhaustivamente, aborda los orígenes del sector (Yanes, 2010), así como con otros muchos trabajos que, dentro de la línea de investigación abierta en la Universidad de La Laguna, han puesto en valor la singular contribución isleña a la Historia de la Radiodifusión Española. Sin embargo, hasta el momento carecíamos de un estudio específico sobre la evolución de los programas ligeros de la parrilla de la programación, reto que nos hemos propuesto abordar en el presente trabajo sin incluir, dada la atención diferenciada que demandan por sus dinámicas comunicativas, los grandes concursos ni los eventos cara al público. A tal fin, y a falta de las grabaciones oportunas, hemos recurrido a los locutores y técnicos sobrevivientes de la época, a los que entrevistamos en profundidad ${ }^{3}$, a las páginas de los periódicos editados en aquellos años, a las que sometimos a un pormenorizado análisis de $\operatorname{contenidos}^{4}$, y a la documentación de $\operatorname{archivo}^{5}$, a cuya luz atemperamos todos los datos recabados. Metodológicamente, hemos recurrido a la microhistoria, esto es, al análisis exhaustivo e intensivo de toda la información obtenida sobre el micro-objeto de estudio desde amplias perspectivas estatales, para lo cual nos hemos valido, a través de la bibliografía disponible, del actual estado de la cuestión de la Historia de la Radiodifusión Española durante el franquismo.

\footnotetext{
Las entrevistas en profundidad, efectuadas entre octubre de 2006 y mediados de 2011, consistieron en largas conversaciones, algunas celebradas en varias sesiones, a las que acudimos con un cuestionario muy sencillo y una actitud muy receptiva hacia todo aquello que nuestros interlocutores nos pudieran desvelar sin estar previsto por nosotros de antemano. Los datos obtenidos los entrecruzamos entre sí y con los que nos suministraron las otras fuentes para garantizar la fiabilidad de aquellos con los que operamos.

$4 \quad$ Además de los diarios El Día (1939...) y La Tarde (1927-1982), consultamos el semanario deportivo Aire Libre (1943-1965) y el mensuario Radio Tenerife (1935-1936), todos ellos editados en la provincia tinerfeña, así como la revista madrileña Discofilia (1956-1957).

5 En concreto, el Archivo General de la Administración (AGA) de Alcalá de Henares y el Archivo Histórico Provincial de Santa Cruz de Tenerife (AHSCT).
} 


\section{La soledad de Radio Club Tenerife en los años de la autarquía}

Para ilustrar las primeras propuestas de entretenimiento de Radio Club Tenerife tras la II Guerra Mundial, nada mejor que detenernos en La hora del radioyente, un espacio que estaba en antena los sábados a las 18:30 horas. Su contenido se reducía a la actuación en el estudio de los solistas y grupos aficionados locales de música ligera, algún que otro humorista y los artistas foráneos que, estando de paso entre la península y Latinoamérica, permanecían algunos días en la isla tras ser contratados por algún empresario. La pésima calidad de los discos microsurco de la época, hacía que los coetáneos prefirieran las actuaciones en directo a la música, según decían, «frita» o «enlatada» ${ }^{6}$, más aún cuando a las deficiencias de las grabaciones y las reproducciones discográficas se sumaba la reiteración de las mismas melodías por los escasos discos disponibles. Poco a poco, estos espacios musicales empezaron a complementarse con la lectura de textos literarios y a proliferar en el tramo inicial de la franja horaria del mediodía, que iba de 12:30 a 14:00 horas, así como en la vespertina de 18:30 a 19:30 horas; no así en la nocturna de 19:30 a 23:00 horas, que hasta finales de los años cincuenta estuvo copada por unas elitistas veladas literario-musicales acordes al elitismo de un medio cuya escasa penetración social ilustran la limitada extensión del tendido eléctrico y los exiguos tres mil aparatos receptores que, por entonces, había en todo el archipiélago (Yanes, 2012).

Una vez consolidada la oferta popular en los tramos horarios del mediodía y la tarde de la parrilla de la programación, ésta se empezó a fragmentaren espacios breves y diferenciados para intercalar entre ellos los anuncios publicitarios que, a duras penas, se conseguían en estos calamitosos años de la autarquía. Los datos parciales y esporádicos que nos han legado la prensa y las fuentes orales nos confirman las ansias del medio de abrirse a la sociedad a tales horas, por más que el corto alcance de la señal, la reducida implantación de la electricidad y los escasos hogares dotados de aparatos receptores se encargaran de frustrar tales objetivos. Dada su asepsia ideológica, las actuaciones en directo de las voces locales de música ligera que imitaban a los cantantes más populares de la época, como Bonet de San Pedro o el trío mejicano Los Panchos, siguió siendo el gancho más adecuado para atraer a las clases populares. Con dicho formato, los Ecos sonoros que salían al aire los domingos entre las retransmisiones de la misa matinal y el Diario hablado de las 13:30 horas de Radio Nacional de España, en los que también intervenían los grupos folclóricos de la isla, debieron batir todas las cuotas de audiencia, por bajas que fueran. Entre las figuras foráneas que visitaron por entonces el estudio de Radio Club Tenerife, especial resonancia tuvieron la coplista Estrellita Castro y los «artistas internacionales» Miriam Kleckova y Gustavo Re ${ }^{7}$.

Al margen de estar lastrados por la injerencia de los ideólogos del régimen, los textos leídos entre las sucesivas actuaciones de los grupos y solistas rezumaban todavía un refinamiento ajeno a los gustos populares. Tal era así porque los temas cultivados en estos espacios eran idénticos a los de las veladas nocturnas dedicadas a la cultura en el sentido más exquisito del término, de los que tan sólo se diferenciaban por adoptar un tono menos solemne o estar en manos de autores noveles. Ilustrativas de ello fueron las Estampas de la tierra, las Siluetas de músicos españoles, las Bio-

Radio Tenerife, agosto de 1935, núm. 4, «Los programas a base de discos».

La Tarde, 2 de abril, 25 de mayo y 1 y 4 de junio de 1946, pp. 4 y 3. 
grafías musicales o las Estampas canarias redactadas por varios escritores isleños y leídas por los locutores de la emisora, o el concurso La voz del joven poeta que, a las mismas horas vespertinas, se emitía con el propósito de captar nuevos valores para la declamación. Otro tanto cabe decir de las dramatizaciones y las lecturas de relatos por entregas que, entre las 19:15 y las 20:15 horas, empezaron a hacerse un hueco, o de las primeras adaptaciones de obras literarias, como La bombonera roja del escritor estadounidense Rex T. Stout (1886-1975) realizada por el locutor Arturo Navarro Grau. Sin duda alguna, el ingrediente menos comercial de la emergente programación ligera fue la semanal Charla en ritmo dedicada al jazz por varios músicos locales a imitación de las que, a partir de 1942, pusiera en antena Manolo Gracia en Radio Nacional de España (Pedrero, 2000: 22).

En definitiva, aunque las franjas horarias del mediodía y la tarde ofrecieron unos contenidos cada vez más asequibles al común de los isleños conforme avanzaron los años de la autarquía, estos siempre se movieron dentro del selecto «tono de Ateneo» y el engolamiento característicos de la radiodifusión de la época. Un indicador desde la antítesis del proceso fue el progresivo retroceso del Día de la Canción que, a partir del 1 de abril de 1942, instituyera el régimen en todas las provincias con el propósito de generar un cancionero que combinara los aires regionales de todo el Estado con la ideología falangista, por más que el engendro siguiera convocándose todavía en 1952. ${ }^{8}$

\section{La propuesta musical de Radio Juventud de Canarias}

Cuando a finales de 1955 Radio Juventud de Canarias inició su andadura con un equipo emisor más moderno y potente que el de Radio Club Tenerife, la industria discográfica española estaba empezando a salir del túnel en el que había permanecido desde el estallido de la guerra civil por el aislamiento internacional y la profunda degradación de los niveles de vida de la población. Un indicador del cambio de coyuntura fue la aparición de la revista madrileña Discofilia, la primera publicación periódica dedicada monográficamente al ramo en España, cuyo número inicial salió al mercado en marzo de 1956, esto es, a los tres meses escasos de la puesta en marcha de la estación-escuela tinerfeña ${ }^{9}$. A nivel cuantitativo, la insignificancia del despegue del sector discográfico quedó patente en las páginas de la propia revista, las cuales testimonian que, en el lustro comprendido entre los años 1952 y 1957, las productoras españolas pasaron de dos, que tan sólo sacaban al mercado medio centenar de discos al mes, a nueve, que apenas rebasaban los doscientos ${ }^{10}$. Dentro del elitismo social del fenómeno, el crecimiento de la producción resulta explicable por las mejoras cualitativas introducidas por entonces en la grabación y la reproducción de la música, las cuales provocaron que empezara a hacerse algo más frecuente el uso privado del pick-up en los hogares de las clases medio-altas del país.

Aunque la dimensión cuantitativa del fenómeno fue a todas luces inapreciable, otra cosa muy distinta fue lo que sucedió a nivel cualitativo, tal y como ilustran los

Ibídem, 31 de marzo de 1952, p. 4.

9 La llegada del nuevo «microsurco a España en 1952» puso las bases, con su posterior consolidación, al «vehículo común y recurrente de difusión de la obra musical» (Pedrero, 2000: 22-24).

10 Discofilia. Noticiario mensual del disco español, Madrid, año II, nº 10, enero de 1957, pp. 9-18. 
cambios experimentados por el sector en el citado lustro 1952-1957. En efecto, en la primera de las fechas, los discos apenas habían evolucionado en relación a los de la República, dado que estaban elaborados con un material frágil y pesado que, al tener un diámetro reducido y girar a 78 revoluciones por minuto, hacía que las audiciones fueran breves y de escasa calidad por el runruneo persistente de la aguja sobre el microsurco. Pero un lustro más tarde, cuando había empezado a emitir Radio Juventud de Canarias, ya había en el mercado español «los discos de larga duración, más resistentes, menos pesados y de superficie más silenciosa, tanto por el material de que están fabricados como por el menor peso y superficie de los zafiros o diamantes que posee la cabeza del pick-up correspondiente... (por lo que)... la época de la llamada música frita puede considerarse definitivamente caducada $\rangle^{11}$. El avance, pues, era doble, dado que incidió tanto en el soporte que supusieron los discos de larga duración de 33 y 45 revoluciones por minuto, como en la reproducción sonora de los mismos. Aunque el disfrute en privado de tal logro sólo estaba al alcance de las clases más favorecidas del país, la radio se encargó de que el beneficio social de este llegara a los sectores urbanos de las clases populares.

Sin duda alguna, Radio Juventud de Canarias, con su infraestructura tecnológica recién montada, fue la primera plataforma desde la que tales mejoras auditivas llegaron a los hogares isleños, toda vez que los medios de Radio Club Tenerife permanecían estancados desde la II República (Yanes, 2009). Es más, como la música fue el eje sobre el que pivotó el grueso de la programación de la flamante estación-escuela por su orientación juvenil, la coincidencia de su puesta en marcha con el salto cualitativo experimentado por la industria discográfica española determinó que la nueva señal articulara en los espacios ligeros una propuesta diferente a la tradicional de la decana de las emisoras isleñas. La fórmula preferida consistió en la apertura de un canal de participación para un segmento concreto de la audiencia, de acuerdo a las expectativas correspondientes, con la oferta complementaria de la música discográfica adecuada, para lo cual se utilizaron desde los incentivos comerciales más originales a las simples dedicatorias de discos, las cuales se convertirían, luego, en uno de los canales de ingresos más lucrativos para todas las emisoras isleñas.

Así, a los pocos meses de estar emitiendo, la estación-escuela tenía en antena cuatro programas de discos dedicados cuyos títulos y horas de emisión hablan por sí solos de sus destinatarios. A saber, Las mañanitas de Radio Juventud dirigido a las amas de casa; la segunda parte de Ballenato, audición infantil, en el que los protagonistas eran los niños; otro programa de tarde de carácter familiar; y, por la noche, La ronda, este dedicado a las parejas de novios. A tono con los gustos y las expectativas de los distintos colectivos iba el tipo de música ofrecida en cada espacio y, en función del número de contrataciones, la duración y la rentabilidad de los mismos. En el caso de La ronda, cuyo formato había traído de la península el jefe fundacional de la programación de la estación-escuela, los ingredientes más característicos eran la sintonía La tuna pasa, la manera de expresar la dedicatoria, «ahora nos trasladamos a la calle... donde nos espera... a quien quiere rondar...», y la interposición, entre canción y canción, de fragmentos de otras piezas de alguna rondalla estudiantil que a muchos oyentes gustaban tanto, o más, que las melodías objeto de las dedicatorias (Yanes, 2009).

Los ingredientes más comunes de los restantes espacios ligeros de la estación-escuela eran un patrocinador al que, normalmente, había que acreditar el consumo

11 Ibídem. 
de sus productos para poder participar, un colectivo social sobre el que giraba la temática tratada, la oferta de discos para el intercambio gratuito de salutaciones y dedicatorias, y una serie de juegos y acertijos incentivados con la concesión de premios. Con dicho formato, que «estimula la participación pasiva de quien escucha la emisión en casa y premia la participación activa de quien juega en el estudio de la emisora» (Balsebre, 2002: 159), se emitieron programas de una hora de duración como Melodías en el hogar, patrocinado por el detergente Mistol, y Espuma musical, patrocinado por Jabonerías Persan de Sevilla, ambos destinados a las amas de casa; Café con música, patrocinado por Cafesa, que en la sobremesa se dirigía, en particular, a los empleados y clientes de las cafeterías; y Cocal premia su buen gusto, consistente en la elaboración de cócteles con las variedades de ron de la casa patrocinadora, Destilerías Cocal ${ }^{12}$.

Este carácter de plataforma de comunicación interpersonal en una época en la que las distancias geográficas separaban tanto a las personas por la inexistencia de teléfonos móviles y los otros cauces abiertos actualmente por las nuevas tecnologías de la información y la comunicación, fue, asimismo, el incentivo central de otra serie de espacios de la estación-escuela que, girando también en torno a la música discográfica, ofrecían a los oyentes la posibilidad de intercambiarse salutaciones a través de las ondas hertzianas. Sin duda alguna, los más celebrados fueron aquellos que posibilitaron a los isleños tejer un fluido intercambio de misivas con sus paisanos y familiares emigrados en Venezuela, lo que unido al fuerte componente afectivo de la línea argumental por la lectura reiterada, entre canción y canción, de las emotivas cartas recibidas, le imprimió un carácter tan entrañable a tales emisiones que se hicieron atractivas para todo el público. Exponentes de la modalidad que precisaba el concurso de una emisora venezolana fueron Mensajes de pueblo a pueblo y Entre dos mundos, espacios grabados antes de su emisión que, desde el otoño de 1961, introdujo en su parrilla Radio Juventud de Canarias ${ }^{13}$. Para entrever la popularidad que se agenció el elaborado en Caracas para Canarias, basta con saber que salía al aireen el prime-time nocturno de los sábados, mientras el recíproco que las islas enviaban a los emigrados, se emitía el lunes siguiente a la misma hora en la otra orilla del Atlántico.

Por consiguiente, tanto el carácter de estación-escuela dirigida a los jóvenes como las mayores prestaciones de su infraestructura técnica, hicieron que los espacios ligeros de Radio Juventud de Canarias difirieran de los que, previamente, había introducido la decana de las estaciones isleñas en dos aspectos. En primer lugar, por el hecho de girar sobre la música discográfica de los recién remozados microsurcos; $\mathrm{y}$, en segundo lugar, por las vías que, para la intervención de la audiencia, abrieron sus jóvenes locutores con los reclamos de diversas casas comerciales. Tal propuesta fue la más singular en este capítulo de la programación de la radiodifusión isleña, toda vez que las nuevas emisoras que, en el verano de 1960, empezaron a emitir con equipos más modestos en localidades interiores de la provincia siguieron la estela de Radio Club Tenerife.

12 Datos suministrados por José Antonio Pardellas Casas (27/01/1938), licenciado en Historia, locutor de Radio Juventud de Canarias y, desde su puesta en marcha en 1964, del Centro Emisor del Atlántico de RNE hasta su jubilación, cuya labor ha sido reconocida con el Premio Ondas 1978 y el Premio Canarias de Comunicación 2007.

13 El Día, 30 de septiembre de 1961, p. 6. 


\section{El apogeo de la estructura "mosaico" en los años centrales del franquismo}

Con la simultánea puesta en marcha, a inicios de los años sesenta, de tres nuevas emisoras domiciliadas en otras tantas localidades ajenas a la capital provincial, La Voz del Valle de La Orotava, Radio Popular de Gǘmar y La Voz de la Isla de La Palma, el sistema radiofónico de la España franquista adquirió su configuración definitiva en la provincia occidental del archipiélago canario. Como todas tomaron como referencia a Radio Club Tenerife, los tramos más ligeros de sus parrillas de la programación también quedaron salpicados por un cúmulo de espacios breves, entre los cuales se intercalaban los anuncios publicitarios. El hecho de que La Voz del Valle y La Voz de la Isla de La Palma pertenecieran al Sindicato Vertical y Radio Popular de Gǘmar a la Iglesia, no supuso diferencia alguna en coherencia con la uniformización tan característica de los medios de comunicación en el franquismo, lo que también se dejó notar en la parte más aséptica de la programación que, a la postre, es la que aquí nos ocupa. Los datos pormenorizados que sobre la emisora de La Orotava nos facilitó el artífice de su programación, el sacerdote José Siverio, resultan sumamente ilustrativos para conocer con detalle las interioridades de nuestro objeto de estudio.

Al margen de su brevedad y de estar a cargo de guionistas y locutores diferentes, estos minúsculos espacios compartieron el hecho de estar elaborados, casi en exclusiva, con la conocida técnica del hombre tijeras de la época, esto es, en base a recortes de textos publicados en libros, revistas y periódicos. Unos versaban sobre asuntos varios, caso de La hoja del almanaque, que ofrecía un comentario sobre algún asunto irrelevante de la actualidad, el santoral, las horas de la salida y puesta del sol, el tiempo meteorológico, una máxima filosófica para invitar a la reflexión, una anécdota y un fragmento del cancionero popular español, casi todo ello extraído del célebre calendario zaragozano; o El mundo redondo, en el que las informaciones sensacionalistas entresacadas de la revista Selecciones (edición en español de la estadounidense Reader's Digest) alternaban con la música y algún que otro comentario sobre asuntos intrascendentes que estaban de actualidad. Con un tono más especializado, estuvieron en antena otros espacios como La rueda del tiempo, centrado en las efemérides del día; o El horóscopo de la semana, cuyos contenidos no sólo eran copiados impunemente de revistas y periódicos ajenos sino, de vez en cuando, inventados por los propios guionistas. ${ }^{14}$

Aunque la audiencia natural de todos estos programas era la mujer, La Voz del Valle tuvo en antena otras propuestas centradas en los típicos contenidos catalogados en la época como específicamente femeninos. Entre las misceláneas podemos citar Ellas, cuyos guiones se ocupaban de la moda, las recetas de cocina, las tareas del hogar, los libros y las biografías de las llamadas «mujeres célebres»; o Nosotras, una revista similar pero dirigida a cultivar, entre las adolescentes y jóvenes, el papel «alienante» (Ramírez, 1975) que la mujer jugaba en la sociedad franquista. Más especializados fueron Señora ama, que consistía en la simple lectura de una receta de cocina, casi siempre, un postre, extraída de algún libro o revista especializada; Mesa

14 Estos detalles tan interesantes para conocer el desenvolvimiento del medio en la época, que no dejaron huellas documentales, nos los facilitó el sacerdote José Siverio Pérez (29/11/1928), recientemente fallecido, uno de los escasos periodistas canarios que en los años centrales del franquismo se tituló en la Escuela Oficial de Periodismo de Madrid, quien fundara en 1969 y dirigiera hasta su jubilación Radio Popular de Tenerife. 
y mantel, que, además de la propuesta culinaria, ofrecía una serie de anécdotas y curiosidades gastronómicas entresacadas, como no podía ser de otra manera, de libros, revistas y periódicos; y Coser y cantar, este centrado en el mundillo del sector textil y en la música que pedían las propias oyentes. La enorme cantidad de caladoras, bordadoras y costureras que había a horas vespertinas, unas para aliviar las economías familiares y otras como simples amas de casa, convirtió a este espacio en el de mayor audiencia del género en el Valle de La Orotava.

Este tramo de la parrilla de la programación hizo un hueco cada vez mayor a las dosis de humor que, al calor de la paulatina apertura del país al exterior, fueron distendiendo poco a poco el tono serio y solemne que presidió la parrilla de la radiodifusión española en los años iniciales y centrales del franquismo. Ilustrativos de la acentuación del proceso conforme avanzaron los años sesenta fueron los espacios titulados Buen humor de aperitivo y Hoy es fiesta que, sucesivamente, estuvieron en antena en La Voz del Valle. Así, mientas el primero de ellos centró sus contenidos en una sucesión de chistes, chascarrillos y curiosidades intercalados con alguna pieza musical jocosa, el segundo, que estaba en antena las tardes dominicales, planteaba a los locutores el reto de bromear y hablar con cierta relajación sobre algún tema a propósito de la letra de alguna canción festiva o una anécdota, cosa que a muchos de ellos les resultaba muy embarazoso porque estaban acostumbrados a leer textos y a cuidar enormemente las formas cuando se ponían delante del micrófono.

Entre los restantes contenidos esparcidos por la franja de la programación que nos ocupa, mención especial merece el relativo al Cupón de los ciegos, dado que, de estar en un principio dentro del Diario hablado de las 21:00 horas, generó luego un programa autónomo para anticipar la información pertinente al público. A tal fin, un técnico de la emisora sindical norteña sintonizaba por onda corta Radio Nacional de España a las 20:00 horas, cuando el sorteo se daba a conocer en directo en Madrid, para que el locutor de turno tomara nota y, de inmediato, diera a conocer el resultado en Canarias. El espacio, que estuvo en antena hasta que la puesta en marcha, en julio de 1964, del Centro Emisor del Atlántico de Radio Nacional de España lo dejó obsoleto, suscitaba tanto interés entre la población adulta que, según nos han afirmado las fuentes orales citadas, hacía que muchos padres de familia abandonaran los espacios de sociabilidad típicos de la época, los bares y las bodegas, para recogerse en sus hogares. De la restante información de servicios, las mismas fuentes nos han desvelado que la más atrayente para la audiencia era la cartelera local de cine con su correspondiente calificación moral por la Iglesia.

\section{El tránsito hacia los primeros espacios de larga duración en Radio Club Tenerife}

Mientras tanto, en coincidencia con el despegue de la bonanza económica de los años sesenta y la puesta en marcha de las tres emisoras ajenas a la capital provincial, Radio Club Tenerife había adelantado la apertura de la estación desde las 11:00 a las 9:00 horas de la mañana. Para cubrir el nuevo tramo matinal hasta que El Ángelus daba paso, a las 12:00 horas, al mediodía, el jefe de la programación encargó a dos jóvenes, el futuro locutor de Radio Nacional de España y Televisión Española en Canarias Mariano Vega Luque y el técnico, que también entraría en la plantilla de Radio Nacional de España, Enrique Martín Braun, el diseño de los formatos, la confección 
de los guiones y la producción diaria de los espacios que empezaron a estar en antena en aquellas tres horas. A cambio, uno y otro percibían una pequeña gratificación y un porcentaje de los anuncios que captaban para intercalar entre los sucesivos espacios, en competencia con sus colegas de Radio Juventud de Canarias que, por entonces, hicieron lo propio. Sobre tales bases, los dos artífices de la programación matinal de la decana de las emisoras isleñas diseñaron un cúmulo de programas de unos quince o veinte minutos de duración, entre los cuales sacaban al aire, bien con la lectura en directo en el estudio o con las cuñas procedentes de las primeras agencias de publicidad de la isla, los anuncios que ellos mismos se encargaban de conseguir.

Para cumplimentar los guiones, Mariano Vega Luque y Enrique Martín Braun se valían a diario de la prensa, cuyas páginas eran el vivero de las noticias de actualidad, y otras publicaciones bendecidas por la censura como el Calendario zaragozano, la citada revista Selecciones o las enciclopedias temáticas de la época que, a tal fin, menudeaban por todas las emisoras del país ${ }^{15}$. Al calor de la permisividad del régimen para con el plagio de las informaciones que habían pasado la criba del censor, el procedimiento era lo que en la actualidad se conoce por «corta y pega», esto es, la transcripción literal de un cúmulo de fragmentos de textos. Luego, a la hora de la realización, los recursos se reducían a la voz de los locutores, el fondo musical, algún efecto sonoro, los toques de xilofón para separar con notas graves o agudas, en función de cada tema, los contenidos tratados, y poco más. Aunque la mayoría de los espacios se emitían en directo, los más elaborados, y alguno que otro de producción externa que servían las agencias publicitarias bajo el patrocinio de firmas comerciales, se grababan previamente. Con estos mimbres, las amas de casa tenían la oportunidad de escuchar, con la intercalación de música y publicidad, consejos sobre sus tareas domésticas, recetas de cocina, las últimas tendencias de la moda, el santoral, la agenda del día, el horóscopo, anécdotas y curiosidades, la cesta de la compra, biografías de personajes célebres, hechos históricos ejemplarizantes $\mathrm{y}$, en definitiva, todo aquello que pudiera venir a cuento para una persona cuyo rol social se reducía a asear el hogar, criar los hijos y hacer placentero el descanso del cabeza de familia.

Con la experiencia atesorada por las mañanas, Mariano Vega Luque y Enrique Martín Braun recibieron el encargo de producir un espacio de larga duración para la noche de los sábados a imagen y semejanza de la conocida Cabalgata fin de semana de la SER, que en Tenerife se podía escuchar, no sin dificultades, con un buen receptor y una potente antena a través de Radio Las Palmas EAJ-50 (Balsebre, 2002: 223-224) ${ }^{16}$. Siguiendo la estela del célebre magacín del chileno Bobby Deglané, y bajo el titular Semáforo en rojo, los dos entusiastas jóvenes diseñaron una serie de concursos, dramatizaciones breves, actuaciones artísticas y eventos abiertos a la participación del público a través del teléfono, alguno de los cuales tan desenfadado como, por ejemplo, ofrecer un obsequio al primero que acercara una tortilla española al estudio. La movilización de todos los locutores y el número tan alto de los invita-

15 Somos deudos de estos datos, irrecuperables sin el concurso de las fuentes orales, de Enrique Martín Braun (23/01/1943), técnico y controlador del sonido de Radio Club Tenerife y, luego, del Centro Emisor del Atlántico de RNE hasta su jubilación.

16 Radio Las Palmas EAJ-50 figuraba entre las emisoras que, en 1953, sacó al aire los 15 capítulos del primer serial de la edad de oro del género en la SER, Lo que no muere, del guionista canario Guillermo Sautier Casaseca, cuyo inesperado éxito de audiencia y, en consecuencia, de captación de publicidad, impulsó el desarrollo de la radio comercial en el franquismo, fenómeno al que no pudieron sustraerse las cadenas institucionales. 
dos para unas emisiones que en su mayoría se sacaban en directo ${ }^{17}$, basta para entrever las dificultades del experimento, más aún cuando la emisora sólo disponía de un diminuto estudio. Años más tarde, cuando Cascada de los sábados sucedió en 1963 a Semáforo en rojo con un mayor respaldo publicitario al calor de la consolidación de la bonanza económica, lo hizo con fecha de caducidad porque al cabo de un año, desde febrero de 1964, el espacio empezó a tropezar con la competencia, nada menos que, de la televisión (Aguado, 1992) en el tramo horario principal de esta.

La otra contribución relevante del tándem formado por Mariano Vega Luque y Enrique Martín Braun al aligeramiento de la programación de Radio Club Tenerife fue Alegre juventud, un espacio inspirado en ¡Discomanía! del chileno Raúl Matas, el pionero «de los programas musicales en la SER, a diario y con cobertura nacional» (Pedrero, 2000: 25), cuya andadura data de 1960. La principal novedad de Alegre juventud consistió en centrar su interés en la vanguardia de la música ligera anglosajona que, en la península, sólo se podía escuchar, y en los escasos receptores dotados de tal señal, a través de las emisoras de frecuencia modulada de las bases militares de los Estados Unidos ${ }^{18}$. La realización de la audaz propuesta en la enclaustrada España de la época resulta explicable porque los dos jóvenes tenían, al calor de las tradicionales relaciones comerciales del archipiélago con el área de la libra esterlina, sus contactos en Londres, quienes les hacían llegar los discos de vinilo de los grupos y solistas que dominaban las listas de ventas en Inglaterra y Estados Unidos. Con tan preciado material, el formato consistía en dar a conocer los lunes, miércoles y viernes, a las 22:00 horas, los éxitos del momento y, los domingos, el hit-parade resultante de la votación semanal de los radioescuchas. Por lo tanto, cuando la aversión franquista a todas las manifestaciones culturales extranjeras aún encorsetaba la música de las emisoras españolas (Balsebre, 2020: 347-351),Radio Club Tenerife hacía sonar en las lejanas Islas Canarias, antes de que pudieran hacerlo sus homólogas de Madrid o Barcelona, el «Love me do» con el que los Beatles comenzaron a revolucionar la música ligera en los países occidentales ${ }^{19}$.

\section{Los magacines de Radio Juventud de Canarias y las emisoras del interior de la provincia}

Aunque se trataba de una emisora «institucional» $\mathrm{y}$, por lo tanto, perteneciente a una de las cadenas del régimen, la $C A R$, el rasgo más distintivo de Radio Juventud de Canarias en los años centrales del franquismo era la frescura que su joven personal introdujo en la parrilla de la programación, evidentemente, dentro de la uniformidad y la gravedad compartidas por la radiodifusión española en la época. Así, cuando los primeros magacines irrumpieron en la estación-escuela, el plagio y el fraude en la

17 Estos jugosos detalles del quehacer cotidiano de la emisora, que no dejaron rastro escrito alguno, proceden de los citados José Antonio Pardellas Casas y Enrique Martín Braun, así como de Juan Antonio Rolo Hernández (13/04/1934), ya fallecido, técnico y controlador de sonido de Radio Club Tenerife hasta su jubilación.

18 Nos referimos a las emisoras de las bases militares estadounidenses de Morón, Rota, Zaragoza o Torrejón de Ardoz. En particular, «Radio Torrejón inició sus emisiones el 1 de septiembre de 1959 (...) y durante años fue un solitario bastión para el rock en inglés; por las emisoras de estos centros militares se filtraron discos, instrumentos e ideas que ayudaron a los incipientes roqueros españoles» (Pedrero, 2000: 24).

19 El dato, suministrado por el propio Enrique Martín Braun, nos lo confirmaron las otras fuente orales utilizadas. 
realización de tales espacios llegaron a tales extremos ante la dejadez reinante que, según nos han desvelado las citadas fuentes orales, era habitual emitir como propias las entrevistas que a los personajes famosos les hacían las emisoras peninsulares, para lo cual sólo se precisaba sintonizar el espacio oportuno a través de una buena antena, grabar todo el contenido, entresacar las repuestas, intercalar las preguntas con la voz propia y, luego, sacar al aire el resultado final del compuesto. Y cuando lo que se quería apropiar estaba en letra impresa, el procedimiento era el de la suplantación de la personalidad, tal y como nos recreó el locutor José Antonio Pardellas, quien, tras hacerse con una entrevista a Manolo Escobar publicada por la revista Ondas, dramatizó su contenido leyendo él las preguntas y un camarero andaluz, que asumió el papel del famoso coplista, las respuestas ${ }^{20}$. Tales prácticas que, como hemos visto con anterioridad, estaban a la orden del día, resultan explicables porque al régimen, una vez que había cribado cuidadosamente la información que circulaba en el país, le tenía sin cuidado la utilización fraudulenta de esta.

Ilustrativo de las cotas históricas alcanzadas por la afición a la «canción española» y las corridas de toros en Canarias, fruto de las directrices uniformadoras de la dictadura, fue el programa Patio andaluz que, el 24 de septiembre de 1958, comenzó su andadura en Radio Juventud de Canarias. Producido y realizado por el locutor extremeño José Francisco Schumann ${ }^{21}$, en el guion alternaba el flamenco, el pasodoble y la copla con la información sobre la temporada taurina, el mundillo de las tonadilleras y las entrevistas a las figuras más destacadas del cante y el toreo ${ }^{22}$, en la mayoría de los casos, pirateadas de emisoras peninsulares o efectuadas con el concurso de algún impostor, como era habitual en la época. Cuando a inicios de octubre de 1961 el espacio cumplía su tercer aniversario, junto al Patio andaluz estaban en antena los magacines de una hora de duración titulados El club del oyente, Cóctel nocturno, Mesa revuelta y, el más insólito y fugaz de todos ellos, Café con leche y gofio ${ }^{23}$, este diseñado para parodiar el homólogo Café, copa y puro de los conocidos periodistas Tico Medina y Julio Camarero, que Radio Club Tenerife recibía grabado de Madrid y emitía los fines de semana.

En las emisoras del interior de la provincia, los magacines de larga duración también aparecieron cuando, avanzados los años sesenta, todas ellas adelantaron sus horarios de emisión a las 8:00 horas. En La Voz del Valle, por ejemplo, el nuevo tramo matinal se subdividió por horas que, sin diferenciar contenidos, conducían otras tantas parejas de locutores, dado que se cubrían con música discográfica, publicidad dirigida a las amas de casa, anécdotas tomadas de publicaciones diversas, algún disco dedicado y, cuando la ocasión lo requería, alguna necrológica de individuos que tenían relevancia social en la zona. En Radio Popular de Güímar, al margen del típico magacín mañanero, adquirieron larga duración algunos espacios de entretenimiento interactivos inspirados en los de Radio Juventud de Canarias, evidentemente, dentro de las limitaciones técnicas de la época, los cuales abrieron vías de relación interpersonal para los jóvenes cuando estas estaban muy limitadas y condicionadas por las diferencias sociales, las distancias geográficas y los tabúes de la época. Sin duda

\footnotetext{
Agradecemos la información a su propio artífice, el citado José Antonio Pardellas Casas.

Aire Libre, 18 de marzo de 1963, p. 5.

Ibídem, 1 de octubre de 1962, p. 5.

23 Detalle facilitad por el propio promotor del espacio, César Fernández-Trujillo de Armas (24/06/1937), ya fallecido, locutor de Radio Juventud de Canarias que, luego, centraría su actividad radiofónica en una agencia de publicidad y en la presentación de eventos diversos.
} 
alguna, el programa que en mayor grado cumplió tal función fueron las Relaciones musicales que, a diario, estaba a disposición de todos los oyentes para que estos, a través de postales y cartas dirigidas a la emisora, se intercambiaran, entre canción y canción, saludos y mensajes a través de las ondas ${ }^{24}$. Con el paso del tiempo, los seguidores más fieles del espacio tejieron unos vínculos cada vez más estrechos entre ellos que, en muchos casos, derivaron en intercambios directos de correspondencia e, incluso, en relaciones de amistad, dado que varios de ellos se visitaron para conocerse personalmente ${ }^{25}$.

\section{La incorporación de Radio Club Tenerife a la cadena SER como emisora asociada}

Una vez inaugurada, en febrero de 1964, Televisión Española en Canarias, e inmersas las ondas hertzianas en una galopante crisis sin solución de continuidad ante la dura competencia audiovisual (Aguado, 1992), la junta directiva de Radio Club Tenerife llegó a un acuerdo para asociarse, al amparo del decreto de 9 de julio de 1954 (Balsebre, 2002: 221-222), a la Sociedad Española de Radiodifusión (SER). A la luz de los datos disponibles, la firma del convenio debió efectuarse a finales de los años sesenta $^{26}$, cuando la crisis de la radiodifusión isleña tocaba fondo.

A partir de entonces, la decana de las emisoras canarias fijó en la parrilla de la programación los espacios que, con un despliegue de medios prohibitivo para el archipiélago, se oían simultáneamente en toda España a través de la SER, los cuales alternaron a lo largo del día con los tradicionales de producción propia que, aunque artesanales, conservaban el gancho de versar sobre el entorno más inmediato de los radioescuchas. La cartera publicitaria, a su vez, se escindió entre los anuncios que se captaban en la isla y aquellos otros que, a escala estatal, contrataban las grandes firmas comerciales para difundir las bondades de sus productos a través de tales emisiones por toda España, la inmensa mayoría, a través de la agencia Publicidad CID de la propia cadena, cuyos beneficios y costos de producción se distribuían entre las emisoras participantes con arreglo a un baremo específico. Aunque la coyuntura era poco favorable para el medio, el hecho de fijar tales productos foráneos en la parrilla de la programación ordinaria, junto a las mejoras de la calidad y el alcance de la señal traída por el remozamiento del equipo emisor, debieron paliar las dificultades para competir por el cada vez más reducido pastel publicitario que llegaba a las ondas hertzianas ante el acaparamiento de los anuncios más suculentos por la televisión.

Sin duda alguna, la principal novedad que para Radio Club Tenerife trajo la incorporación a la SER fue la llegada de los espacios de larga duración conducidos

24 Estos datos referidos a Radio Popular de Güímar proceden del técnico José Díaz Delgado (16/11/1939), ya fallecido, quien haría de esta actividad su profesión de por vida.

25 Por consiguiente, Relaciones musicales y los espacios radiofónicos diseñados con un formato similar en aquella época se pueden considerar, algo así como, la prehistoria de la plataforma comunicativa que, en la actual aldea global, ha introducido Internet, cuando los contactos previos al conocimiento personal se hacían públicamente a través de las ondas hertzianas dentro de un ámbito social y geográfico muy reducido, el cubierto por la emisora oportuna.

26 Al respecto, debemos aclarar que la fecha más antigua que hemos podido constatar documentalmente sobre la presencia de Radio Club Tenerife entre las estaciones asociadas a la cadena SER data de 1970 (AGA, sección Presidencia, caja 52, legajo 16405). 
por una voz popular en todo el Estado que, al calor de su atracción, fidelizaba la audiencia femenina a través de los lazos de empatía tejidos entre los dos polos de la relación comunicativa. El género y, con él, las emisiones en cadena habían iniciado su andadura en la península en 1948 debido, de un lado, a la llegada de los primeros magnetófonos que permitieron grabar los programas para reproducirlos por las distintas emisoras; y, de otro, a la creciente demanda delas firmas comerciales de una plataforma publicitaria estatal para lanzar a los cuatro vientos sus productos en toda España. A renglón seguido, desde que la Compañía Telefónica instaló, en 1949, el primer circuito de líneas microfónicas para posibilitar la conexión de las distintas emisoras de la SER con Radio Madrid EAJ-7, salió al aire el primer programa en directo de difusión estatal, Cabalgata fin de semana, la célebre revista de variedades de las noches de los sábados que Radio Club Tenerife versionara, con sus medios artesanales, en la primera mitad de la década de los sesenta. A finales del franquismo, aunque los programas en cadena se habían diversificado, el más aceptado seguía siendo el magacín, esto es, un «contenedor de distintos espacios (concurso, entrevista, música, dramático) conectados entre sí por la figura de un único locutor-presentador y una misma propuesta narrativa» (Balsebre, 2002: 154), dirigido a horas matinales, específicamente, a la mujer. Con ellos, la radiodifusión isleña empezó a dejar atrás la etapa autóctona para equipararse, cada vez más, al medio a escala estatal.

\section{Conclusiones}

La reconstrucción de la programación de entretenimiento en la radiodifusión canaria a lo largo del franquismo nos ha permitido atisbar, grosso modo, cuatro etapas sucesivas cuyas característicos guardan coherencia con la evolución socioeconómica del archipiélago en aquellas cuatro décadas. A saber, a) El paulatino afloramiento de tales contenidos en la II Guerra Mundial, conforme el viraje ideológico del régimen en favor de los Estados Unidos tras la debacle nazi en Stalingrado se acentuaba, con su paulatino afianzamiento entre los resquicios del grave y solemne discurso del medio en los años de la autarquía; b) La consolidación de la propuesta desde los años cincuenta con una estructura atomizada en espacios breves, en paralelo a las primeras medidas aperturistas del régimen, al tiempo que, con la inauguración de Radio Juventud de Canarias, emergía en la segunda mitad de la década otra fórmula basada en la música discográfica y la interactividad con la audiencia; c) La irrupción de los magacines de producción propia desde el inicio del boom turístico en 1960, cuando las emisiones se adelantaron a las 9 o, incluso, las 8 de la mañana, tanto de los matinales dirigidos a la mujer como de los nocturnos diseñados para toda la familia; y d) La desaparición de estos últimos tras la llegada de la televisión en febrero de 1964, al no poder competir con el medio audiovisual a tales horas, al tiempo que irrumpían los matinales producidos en directo en la península con más medios y el sobreañadido gancho de estar conducidos por una voz popular en toda España. Ello, unido a la acentuación de la bonanza económica, hizo que la radio isleña empezara a mimetizarse, cada vez más, con la del resto del Estado.

A la vista del estado de la cuestión a escala estatal, la investigación ha desvelado algunas especificidades isleñas que enriquecen los conocimientos del medio en la España franquista. Así, cuando en las islas estaba vigente la estructura "mosaico" en la programación, los enclaves punteros de la península ya habían dado paso, a partir 
del Café de tarde que en 1947 pusiera en antena Joaquín Soler Serrano en Radio España de Barcelona, tanto los magacines de sobremesa como los llamados «programas-regalo» (Balsebre, 2002: 156 y 159) que Radio Juventud de Canarias introdujera tras su puesta en marcha a finales de 1955. La parcelación de la franja horaria dedicada en Radio Club Tenerife al entretenimiento en un cúmulo de micro-espacios y voces diversas iba de la mano de una audiencia muy restringida y elitista por los escasos aparatos receptores disponibles y la reducción de las emisoras del archipiélago a Radio Club Tenerife, en la provincia occidental, y Radio Las Palmas, en la oriental, ambas de baja potencia. Con el crecimiento económico de los años sesenta fue cuando, en coincidencia con la irrupción de los magacines de larga duración, el medio empezó a llegar a las clases populares, al tiempo que, desde la inauguración del Centro emisor del Atlántico de Radio Nacional de España en julio de 1964, los isleños de las siete islas pudieron escuchar, por vez primera, una misma programación que, además, compartían con el resto de españoles. Al margen de estas disimilitudes centro / periferia que son extrapolables, con los matices propios de cada lugar, al resto del Estado, la especificidad más singular del caso isleño derivó de la tradicional apertura de su economía al exterior, por limitada que estuviera por entonces, lo que, entre otras cosas, posibilitó la llegada directa a las islas, no a través de las emisoras de las bases estadounidenses como sucediera en la península (Pedrero, 2000: 24), de la música ligera anglosajona de vanguardia.

\section{Referencias bibliográficas}

Aguado Monjas, G. (1992). La Televisión Pública en Canarias. Tesis doctoral. Madrid: Universidad Complutense de Madrid.

Balsebre Torroja, A. (2002). Historia de la Radio en España (1939-1985), vol. II. Madrid: Ediciones Cátedra.

Díaz Sánchez, L. (1999). La radio en España, 1923-1997. Madrid: Alianza Editorial.

Gómez García, S. (2012). Del Yugo a la Cruz. Radio Nacional de España: una radio en transición (1945-1951), Área abierta, 12 (3), 3.

Gómez García, S. et al (2010). Oír la radio en España: el entretenimiento radiofónico en España durante el franquismo, Congreso AE-IC, 3, 4 y 5 de febrero de 2010, Universidad de Málaga.

Gómez García, S. y Cabezas Deogracias, J. (2013): Oír la radio en España: Aproximación a las audiencias radiofónicas durante el primer franquismo (1939-1959), Historia crítica, $n^{\circ} 50$, pp. 104-131.

Pedrero Esteban, L. M. (2000). La radio musical en España. Historia y análisis. Madrid: Instituto Oficial de RTVE.

Ramírez Domínguez, J. A. (1975). El cómic femenino en España. Arte sub y anulación. Madrid: Editorial Cuadernos para el Diálogo.

Sebastián Morillas, A. (2017): El papel de la publicidad en España durante el franquismo: el nacimiento de la sociedad de consumo, Cuadernos. Info, no 41, pp. 209-226.

Yanes Mesa, J.A. (2007). Los orígenes de la COPE en Canarias. "Radio Popular de Güimar», 1960-1969. Santa Cruz de Tenerife: Ediciones Baile.

- (2009). Las ondas juveniles del franquismo. "Radio Juventud de Canarias», 1955-1978. Santa Cruz de Tenerife: Ediciones Baile del Sol y Dirección General del Libro, Archivos y Bibliotecas del Gobierno de Canarias. 
- (2010). Los orígenes de la radiodifusión en Canarias. "Radio Club Tenerife», 1934-1939. Santa Cruz de Tenerife: Ediciones Baile del Sol y Dirección General del Libro, Archivos y Bibliotecas del Gobierno de Canarias.

- (2012). La radiodifusión privada en Canarias durante el franquismo. «Radio Club Tenerife», 1939-1975. Islas Canarias: Ediciones Densura.

Yanes Mesa, J. A.; Rodríguez Borges, R. F. (2007).La radiodifusión sindical del franquismo. «La Voz del Valle» en las Islas Canarias, 1960-1965. La Orotava: Ayuntamiento de La Orotava, Cabildo de Tenerife y Dirección General del Libro, Archivos y Bibliotecas del Gobierno de Canarias.

Yanes Mesa, J. A.; Hernández Cabrera, E. (2011): «La Voz de la Isla de La Palma», 19601978. La radiodifusión del sistema comunicativo más singular de Canarias en el franquismo. Puntagorada (La Palma): Ediciones Alternativas. 